\title{
Description of an adult spina bifida administrative sample: findings from the United States Veterans Administration Spina Bifida Health Care Program database Melissa Danielson*, Judy Thibadeau and Vincent Campbell
} \author{
E-8, Atlanta, GA 30333, USA \\ Email: Melissa Danielson* - MDanielson@cdc.gov \\ * Corresponding author \\ from 52nd Annual Meeting of the Society for Research into Hydrocephalus and Spina Bifida \\ Providence, RI, USA. I I-I4 June 2008 \\ Published: 3 February 2009 \\ Cerebrospinal Fluid Research 2009, 6(SuppI I):SI5 doi:I0.II86/I743-8454-6-SI-SI5
}

Address: National Center for Birth Defects and Developmental Disabilities, Centers for Disease Control and Prevention, 1600 Clifton Rd NE, MS

This abstract is available from: http://www.cerebrospinalfluidresearch.com/content/6/SI/SI5

(C) 2009 Danielson et al; licensee BioMed Central Ltd.

\section{Background}

One challenge to understanding the natural history of spina bifida is there are very few sources of data on larger populations of adults with spina bifida. The use of administrative datasets may help to fill this gap. Though there are limitations to the use of administrative data, they can provide information on many individuals with spina bifida, potentially illuminating patterns of diagnoses, treatments and associated payments.

\section{Materials and methods}

The United States Veterans Administration (VA) administers a program to provide coverage for all health care related to spina bifida to children of Vietnam War veterans who were born with the condition. We have analyzed data from this program to evaluate the demographics of this population, common diagnoses for inpatient admissions, frequency of doctor visits, treatments, prescription drugs and purchase of durable medical equipment, and associated payments.

\section{Results}

There are 1,221 beneficiaries served by this program, with 908 having filed health care claims between the inception of the program (October 1, 1997) and March 31, 2006. Most beneficiaries are age 18 years and older (94\%) and are in the highest severity category according to VA designation (68\%). Over 200,000 claims have been filed total- ling nearly $\$ 63$ million in payments. The median number of claims per beneficiary is 160 , and the median amount paid per beneficiary is $\$ 23,000.42 \%$ of beneficiaries had at least one inpatient admission since inception of the program, with a median length of stay of 4 days and neurological diagnoses being the most common cause of admission. $77 \%$ of beneficiaries had claims for doctor visits, with a median of 1.7 doctor visits per year. $61 \%$ of beneficiaries had claims for prescription drugs, with a median of 6 prescriptions per year and 8 unique prescriptions over the course of the program. In general, health care utilization is highest among younger beneficiaries, decreases for those who are between 18 and 35 years of age, then increases for those who are older than 35 years.

\section{Conclusion}

Analysis of data from the VA Spina Bifida Healthcare Program provides a unique opportunity to evaluate the experiences a large group of adults with spina bifida. Observations from this dataset may help guide research for adults with spina bifida, a population that continues to increase in size as more effective treatments during childhood extend life expectancy. 